\title{
A INVENÇÃO DO OUTRO: O “CAMPO" EM PESQUISAS SOBRE LIVROS DIDÁTICOS DE HISTÓRIA
}

\section{THIAGO RANNIERY}

Doutor em Educação pela Universidade do Estado do Rio de Janeiro. Professor do Programa de Pós-Graduação em Educação, Universidade Federal do Rio de Janeiro. Integra o Laboratório

Núcleo de Estudos Curriculares - LaNec/ UFRJ e o Grupo Currículo e Diferença da Universidade do Estado do Rio de Janeiro. ORCID: 0000-0003-4399-2663. E-mail: t.ranniery@ gmail.com

\section{RENATA TELHA FERREIRA DE OLIVEIRA}

Mestranda em Educação na Universidade Federal do Rio de Janeiro. Integra o Laboratório Núcleo de Estudos Curriculares - LaNec/ UFRJ. Professora de História da Rede Municipal de Educação do Rio de Janeiro. ORCID: 0000-0002-9385-5109. E-mail: renatatelha@gmail.com 


\section{A INVENÇÃO DO OUTRO: “campo" em pesquisas sobre livros didáticos de história}

Este artigo tem por objetivo discutir como pesquisas com/sobre livros didáticos de História participam da disputa por significação de "campo", cujo processo de fabricação está marcado por elementos da cidadania, do desenvolvimento, do progresso e do binômio inclusão/exclusão. Argumentamos que isto ocorre porque tais pesquisas educacionais, fazendo-se luta política com o fim de assegurar direitos para as "populações do campo", acabam por acessar mecanismos discursivos de produção do "Outro", alterizado, a partir do qual funciona a matriz de pensamento constituída nas malhas de poder da modernidade/colonialidade. Assim, ainda que a disputa por ressignificação do "campo" seja o de desmontar o binário campo/cidade e, portanto, escapar daqueles sentidos que o alocaram em condição de subalternidade, paradoxalmente, partilha-se das mesmas estratégias que o produzem como lugar de falta, de passividade, de disputa por terras, de conflitos e mortes. Isto é, parte-se do mesmo recurso de fabulação de categorias que, em posições hierarquicamente distintas, fazem-se contingencialmente dicotômicas, conflitantes, excludentes. De modo ambivalente, desta repetição emerge outro binário - rural/campo -, que caracterizará os argumentos de parte dos trabalhos analisados. Afim de sobrepujarem-se às ideias de urbanização e industrialização que marcariam o "campo" como outro da "cidade", os textos analisados parecem assentir da lógica em que o "campo" é outro, cuja identidade precisa ser elaborada, reafirmada e defendida, o que tornaria potente a reivindicação por direitos sociais como, por exemplo, acesso à terra e educação, ou mesmo à vida. Acessar o recurso da cidadania, via políticas de identidade, por meio dos discursos educacionais, produziriam como efeito, então, reconhecimento do Estado e, portanto, garantias através dos textos legais. Entretanto, parece-nos que, a despeito de tais projetos emancipatórios para as "populações camponesas", as possibilidades de sentidos de "campo" permanecem restritas quando os modos de produzir inteligibilidade da luta política da pesquisa em educação ainda constituem-se segundo uma ontologia moderna e colonial, que acabam por simplificar e tornar homogêneas categorias, trajetórias e temporalidades.

Palavras-Chave: Currículo. Livro Didático de História. Modernidade. Colonialidade.

\section{THE INVENTION OF OTHERS: the "field" in research on textbooks of History}

This article aims to discuss how research with/on History textbooks dispute the meaning of "country", whose fabrication process is marked by elements of citizenship, development, progress and the binomial inclusion/exclusion. We argue that this is because such research, by making a political struggle to secure rights for the "rural populations", accesses discursive mechanisms of production of the "Other," in which the matrix of thought functions in the power meshes of the modernity/coloniality. Although the dispute over the re-signification of the "country" is by dismantling the binary city/rural and, therefore, escaping from those senses that allocated it in the condition of subalternity, paradoxically, it shares the same strategies that produce it as a place of failure, passivity, land disputes, conflicts and deaths. It starts from the same resource of construction of categories that, in hierarchically distinct positions, are made contingently dichotomous, conflicting, excluding. In an ambivalent way, from this repetition emerges another binary - rural/country-, which will characterize the arguments of part of the works analyzed. In order to overcome the ideas of urbanization and industrialization, the texts analyzed seem to be based on the logic in which the "country" is an Other, whose identity must be elaborated, reaffirmed and defended, which would make the claim for social rights potent. access to land and education, or even life. It seems to us that the possibilities of senses of "country" remain restricted when the modes of producing intelligibility of the political struggle of education research still constitute a modern and colonial ontology that simplify and homogenize categories, trajectories and temporalities.

Key-words: Curriculum, textbook of History, field, modernity / coloniality. 


\section{LA INVENCIÓN DEL OUTRO: el "campo" em investigaciones sobre libros didácticos de Historia}

Este texto tiene por objetivo discutir cómo las investigaciones con / sobre libros didácticos de Historia disputan significación de "campo", cuyo proceso de fabricación está marcado por elementos de la ciudadanía, del desarrollo, del progreso y del binomio inclusión / exclusión. Argumentamos que esto ocurre porque tales investigaciones, haciéndose lucha política con el fin de asegurar derechos para las "poblaciones del campo", acceden a mecanismos discursivos de producción del "Otro", en el que funciona la matriz de pensamiento constituida en las mallas de poder modernidad / colonialidad. Aunque la disputa por resignificación del "campo" sea por desmontar el binario campo / ciudad y, por lo tanto, escapar de aquellos sentidos que lo asignaron en condición de subalternidad, paradójicamente, se comparte las mismas estrategias que lo producen como lugar de falta, pasividad, de disputa por tierras, de conflictos y muertes. Se parte del mismo recurso de fabricación de categorías que, en posiciones jerárquicamente distintas, se hacen contingentemente dicotómicas, conflictivas, excluyentes. De modo ambivalente, de esta repetición emerge otro binario - rural / campo -, que caracterizará los argumentos de parte de los trabajos analizados. En cuanto a las ideas de urbanización e industrialización, los textos analizados parecen compartir de la lógica en que el "campo" es otro, cuya identidad necesita ser elaborada, reafirmada y defendida, lo que haría potente la reivindicación por derechos sociales como, por ejemplo, acceso a la tierra y educación, o incluso a la vida. Nos parece que las posibilidades de sentidos de "campo" permanecen restringidas cuando los modos de producir inteligibilidad de la lucha política de la investigación en educación todavía se constituyen según una ontología moderna y colonial, que simplifica y homogeneiza categorías, trayectorias y temporalidades.

Palabras claves: Currículo. Libro didáctico de Historia. Campo. Modernidad/ colonialidade. 


\section{A INVENÇÃO DO OUTRO: O “CAMPO” EM PESQUISAS SOBRE LIVROS DIDÁTICOS DE HISTÓRIA}

\section{Com quantas mortes no peito se faz a seriedade, senhor cidadão? ${ }^{1}$}

A cidadania, literalmente, caiu na boca do povo. Mais ainda, ela substituiu o próprio povo na retórica política. Não se diz mais 'o povo quer isto ou aquilo', diz-se 'a cidadania quer'. Cidadania virou gente. (CARVALHO, 2017, p.13).

A epígrafe traz as palavras do historiador José Murilo de Carvalho (2017) e, talvez, com algum exagero, enuncia a importância que os debates sobre cidadania e a defesa de sua garantia adquiriram no espaço público após o fim da ditadura civil-militar, em 1985 - inclusive, adjetivando a Constituição de 1988. Entretanto, essa "cidadania-gente" parece ter se mostrado caprichosa e com personalidade complexa. Participação política, liberdade e igualdade, basilares para a realização plena desta cidadania de acordo com Carvalho (2017), compreendeu-se poder coexistirem sem a efetivação completa de todos os seus elementos. Nas palavras do historiador, "é um ideal desenvolvido no Ocidente e talvez inatingível" (CARVALHO, 2017, p.15); mas que segue sendo perseguido a realizar-se na efetivação de direitos políticos, civis e sociais. Nesse sentido, ressaltam-se os vínculos entre os discursos educacionais - também os produzidos pelas pesquisas da área - e a cidadania, enquanto projeto a concretizar-se, constituindo ideias como as que estão presentes em Carvalho (2017, p.17), ou seja, de que a educação é "pré-requisito para expansão de outros direitos" e "a ausência de uma população educada tem sido um dos principais obstáculos à construção da cidadania civil e política". No percurso deste texto, esses nexos configuram o lastro de fundo da discussão que iremos travar, pois, em nosso entender, o vínculo entre educação e cidadania contribui não apenas para o apagamento de diferenças, mas a sua conversão em um outro alterizado.

Retomamos o questionamento já posto por Anhorn e Costa (2011, p.128) para dele partir: "afinal, a emergência tanto da escola pública como da disciplina escolar história, não se insere em uma pauta mais ampla de construção e consolidação dos Estados Nacionais em pleno regime moderno de historicidade?", isto é, dá-se numa concepção de "tempo aberto ao futuro e levado

${ }^{1}$ Referência à música Senhor Cidadão, de Tom Zé. 
pelo progresso" (HARTOG, 2017, p.19). Tanto a escola quanto a disciplina história passam a contribuir para a consolidação destes Estados nacionais na medida em que a elas são atribuídos papéis como, por exemplo, o de fortalecimento de vínculos identitários nacionais e/ou de lealdade ao Estado. Da produção do sentimento de pertencimento ao Estado nacional e da pretensa conformação aos seus códigos, emergiriam como efeito cidadãs e cidadãos. Como assegura Macedo (2017, p. 546), a ideia de cidadania tanto sanciona o discurso da educação como um projeto de formação de identidade, quanto, como seu corolário, "se apresenta como o passaporte para toda e qualquer intervenção educativa" (MACEDO, 2017, p.546).

Não seria, pois, esse discurso do desenvolvimento de identidades, para pensar com Escobar (2007), um efeito ecoante da forte a crença colonial do país que ainda não se tornou? Do "gigante que não acordou" e, portanto, não conheceu as benesses do progresso que lhe fora prometida ou de imaginação parnasiana de vocação para um futuro de grandeza de um país impávido e colossal? Não seria também um modo de reiterar jogo distintivo da condição de quem é ou não cidadão - ou de quem, por meio da escolarização, tornar-se-á -, entre civilização e atraso tão típico da modernidade? Ou, mais provocativamente, pensando com Lugones (2014), de produzir distinções entre humanos e não-humanos? Sem naturalizar o termo modernidade, cabe dialogar com Escobar (2003), quando destaca a formação dos Estados nacionais e os processos que desencadeiam com relação, por exemplo, à organização da vida social. Ou seja,

[...] A modernidade introduz uma ordem baseada nos constructos da razão, do indivíduo, do conhecimento especializado e dos mecanismos administrativos ligados ao Estado. Ordem e razão são vistos como fundamentos para a igualdade e a liberdade, possibilitando assim a linguagem do direito. (ESCOBAR, 2003, p.56)

Ao pensar o Estado, que se constitui e se atualiza numa lógica de modernidade/colonialidade (Escobar, 2003; Grosfoguel, 2008), e que, portanto, encena a ficção da racionalidade, da passagem entre natureza e cultura, acessar a cidadania faria cumprir garantias da superação da condição de subalternidade? Tal questão, podemos cotejá-la com a seguinte fala de Aílton Krenak (2018), em recente entrevista, ao abordar a complexa relação entre o Estado, as legislações vigentes no período da ditadura civil-militar e os movimentos indígenas, formados e fortalecidos naquele período, no exílio. Em suas palavras, "até para conquistar esse status o pobre tem que ir fundo, tem que ralar na mais desolada condição de cidadão para se erguer como um sem-terra" (KRENAK, 2018, p.17). Sendo cidadania um signo de intensas disputas, Tom Zé, cuja letra figura como título desta introdução, nos oferece um lampejo de sentido: amarga, cuja seriedade (ou legitimidade) 
- marcada pelos textos legais, por exemplo - é constituída pelas mortes no peito de quem não adquire a chancela da cidadania. Na briga eterna do mundo burocrático do reconhecimento estatal, a normatividade fere os que "[...] rondam o arame / das cercas / alumiados pela fogueira /dos acampamentos. / Eles rondam o muro das leis [...]" (TIERRA, 1996). As cercas - e não há, como insistiremos, metáfora, aqui - estabelecem a distinção entre quem é ou não é "cidadão".

Seguindo a mesma lógica usada por Butler (2018) para pensar o "povo", desse mesmo movimento deriva a produção de quem seja capaz de qualificar como cidadão ou cidadã e dos que vão defender a cidadania para grupos possivelmente em condição de exclusão de direitos sociais. A cidadania para todos, portanto, não abdicaria da relação inclusão/exclusão uma vez que "ainda estamos fazendo suposições implícitas sobre quem está incluído [...] o que Chantal Mouffe e Ernesto Laclau descreveram [...] como a exclusão constitutiva" (BUTLER, 2018, p.10). Assim, pensando também como Macedo (2017, p.541) que "a inclusão com a estratégia perversa da exclusão: ela visa a excluir a própria possibilidade da exclusão", podemos outra vez citar Tierra (1996) para pensarmos a relação ambivalente dos lados da cerca: "[...] O sonho vale uma vida? / Não sei. Mas aprendi / da escassa vida que gastei:/ a morte não sonha. / A vida vale tão pouco/ do lado de fora da cerca/ A terra vale um sonho?/ A terra vale infinitas/ reservas de crueldade,/ do lado de dentro da cerca [...]" (TIERRA, 1996). Como apostar nas cercas pode produzir vida? Não é possível simplesmente rejeitá-las. Talvez seja preciso apostar na vida para nos movimentarmos por elas ou desconstruí-las, ainda que contingencialmente.

\section{Percurso de uma pesquisa sobre pesquisas com livros didáticos de História}

Todo esse preâmbulo nos permite situar a questão sobre a qual esse texto se debruça: a invenção do campo em pesquisas sobre livros didáticos de História como a invenção de "um outro alterizado", cujo processo de fabricação está marcado por elementos da cidadania, do desenvolvimento, do progresso e do binômio inclusão/exclusão. De fato, no Brasil, no início do século XX, os livros didáticos correspondiam a apenas dois teç̧os dos livros publicados (CHOPPIN, 2004). Entretanto, com o Plano Nacional do Livro Didático (PNLD) e, posteriormente, o PNLD-Campo, o livro didático ganhou notoriedade em políticas públicas que incentivam sua produção e distribuição às escolas públicas do país, onde foram gastos, por exemplo, cerca de 1,3 bilhão de reais em 2017, segundo dados do Fundo Nacional de Desenvolvimento da Educação (FNDE) - cifras que desde o início dos anos 2000 tem constituído cerca de $60 \%$ da produção de todo faturamento da indústria livresca no país (Silva, 2012). Desde então, segundo Cassiano (2017), o governo brasileiro tornou-se o maior comprador de livros didáticos do mundo, atraindo a atenção de empresas estrangeiras para o mercado brasileiro de comercialização de material didático, como o grupo espanhol Santillana, que adquiriu a Editora Moderna, e o grupo franco-

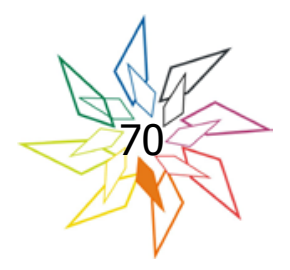


espanhol Anaya-Hachete Livre, que passou a controlar 51\% das ações da Escala Educacional (SILVA, 2012). Não é de se estranhar que tenha havido alargamento do interesse acadêmico em acompanhar a atuação do PNLD e, também por isso, avolumam-se trabalhos e artigos sobre os seus mais diferentes aspectos. Sua complexidade se amplifica quando consideramos as condições que viabilizam a elaboração, produção, circulação, distribuição e uso desses livros.

Porém, vamos, neste texto, acrescentar outra camada a essa discussão, entendendo que as pesquisas sobre e com livros didáticos de História também participam discursivamente desse embate de sentidos. Nesse deslocamento, desejamos explorar como o "campo" aparece nas próprias pesquisas com/sobre livros didáticos de História. Esse questionamento funcionou como disparador para realizar um movimento de zigue-zaguear entre o espaço de nossa pesquisa e outras já foram realizada, possibilitando-nos desconfiar, estranhar, inventar, negociar sentidos, como sugerem Dagmar Meyer e Marlucy Paraíso (2013). Pensando a tarefa da crítica, fazendo ecoar Stengers (2018), buscamos desacelerar o raciocínio sobre temas que parecem caros ao projeto de cidadania sancionado pela educação de modo a colocar as categorias conceituais com que operamos em suspenso, como é o caso da pesquisa com livros didáticos de História.

Sem a pretensão de fazer uma cartografia total, não nos acompanhou a preocupação em efetuar um mapeamento que esgotasse as pesquisas da área ou alcançasse algum tipo abordagem totalizante sobre a temática desenvolvida. Interessa-nos, aqui, caracterizar como as pesquisas cuja temática central seja o "campo" em livros didáticos de história vem também "inventando o campo". Nesse sentido, os quatro trabalhos de pesquisa que abordaremos foram acessados pelo Catálogo de Teses e Dissertações da Coordenação de Aperfeiçoamento de Pessoal de Nível Superior (CAPES) e pela Biblioteca Digital Brasileira de Teses e Dissertações (BDTD), utilizando como referência os anos de 1996 a 2017. O mapeamento foi realizado, utilizando a combinação das seguintes palavras-chave - livro didático, história e campo - e, obteve como resultado as dissertações de Negri (2017), Vieira (2013) e Carmo (2015) e a tese de Chaves (2015) ${ }^{2}$. E, sabemos que poderá parecer repetitivo, mas nossa conversa com esses textos objetiva suspeitar das categorias que nos constituem enquanto pesquisadores em educação. E, assim, trata-se de "jogar para o alto aquela segurança e conforto presentes dentro da ontologia disponível" (BUTLER, 2013, p.172) que tais categorias conformam.

\footnotetext{
${ }^{2}$ Tendo apenas estes trabalhos, como resultado, leva-nos a ponderar que a relação foi pouco explorada como tema na área de Educação. É importante destacar, todavia, que, devido não só a imprecisão, mas à liberdade que os/as pesquisadores/as têm de escolherem as palavras-chave que irão identificar seus textos, a quantidade de trabalhos, que ao menos tangencie este tema, pode ser maior.
} 
Nosso argumento, deste modo, se espraia em algumas ponderações relacionadas sobre como quatro pesquisas realizadas na área da Educação sobre o "campo" em livros didáticos de História trazem o movimento de um campo discursivo educacional que alude às políticas de identidade, acionando a marca contingencialmente homogeneizadora e hegemônica de estadonação, para reconhecimento da condição de cidadania e, assim, fazer funcionar à linguagem de acesso à direito. Além disso, contribuem para fixarem sentidos de "campo", uma vez que restringem "campo" às discussões que dicotomizam e, logo, hierarquizam categorias combinadas como campo/cidade e campo/rural. Tais pesquisas são, ainda, atravessadas, como que por efeito, pelos projetos emancipatórios para as populações do campo por meio da educação - "postura salvacionista que sobrevive com força na educação, subscrevendo que nunca as vidas, que insiste em descrever como abjetas, outras, diferentes, seja lá que nome for, serão parte da realeza" (RANNIERY, 2018, p.3).

\section{Atualização de binários na disputa pela cidadania}

Da tese de Chaves (2015) emergem sentidos de "campo" que, inicialmente, parecem caracterizar a Educação e a escola do campo enquanto política de Estado e que, posteriormente, agrega-se ao debate das políticas de identidade e, assim, passa a ser pensada amalgamando-se a argumentos em favor do reconhecimento da "identidade camponesa". Na construção desse argumento, destaca-se uma abordagem histórica e linear - posto que opta pela análise de uma série cronológica de textos legais - que teria como marco a década de 1920, quando são aprovados projetos políticos específicos para evitar o êxodo rural e tornar possível a fixação das "populações do campo", que migravam para as cidades atraídas pela industrialização e urbanização iniciados no século XIX. Com projetos pedagógicos específicos para estes grupos, com programas e métodos voltados às necessidades dessas populações, a educação, sob tal ponto de vista, fora defendida como o instrumento do progresso capaz, não apenas de manter a mão de obra no campo, como de mudar as condições materiais de suas populações. Tais iniciativas, no entendimento de Chaves (2015, p.56), idealizam que "pela educação o camponês tomaria consciência de suas origens e, como consequência, transformaria seu presente em prosperidade".

O movimento migratório do "campo" para a cidade ao longo das décadas de 1930 a 1950, ganha ainda mais destaque. E, com isso, dá-se enfoque ao processo de industrialização e sua relação com as políticas públicas educacionais - como as do governo de Getúlio Vargas, a partir de 1937, quando se volta para a concepção de escola rural, com a criação da Sociedade Brasileira de Educação Rural, sob o foco de "expansão do ensino e preservação da arte e folclore rurais", "sem descuidar dos princípios de disciplina e civismo" (LEITE, 2002, p. 30-31 apud CHAVES, 2015, p.58) e de transformar o camponês brasileiro em um fazendeiro aos moldes estadunidense,

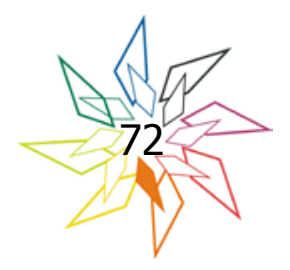


"mediante eficaz e intensivo programa educativo de base" (LEITE, 2002, p.33 apud CHAVES, 2015, p.58) após a Segunda Guerra Mundial. Sem deixar de mencionar a municipalização das escolas rurais após a aprovação da Lei de Diretrizes e Bases (LDB) 4.024/61 e a substituição das professoras normalistas por técnicos durante o período da ditadura civil-militar (1964-1985), recoloca a atenção na industrialização e na urbanização como entraves ao estabelecimento de um projeto educacional efetivo para o "campo", demarcando como exceção aquele realizado por Paulo Freire e aqueles advindos do fortalecimento de movimentos sociais rurais da década de 1970, e consolidados politicamente após a abertura, na década de 1990 - período marcado por pressões para substituir o conceito de educação rural por educação do campo. A partir desse período, o termo "rural" passa a ser identificado pelos movimentos sociais com a lógica mercadológica do agronegócio, o que tornaria impossível de caracterizar a realidade de quem vive "no campo" e "do campo" sem concentrar renda ou lucro. Esta iniciativa de construção da contraposição entre "rural" e "campo" interessa-nos, pois aponta para um projeto de sujeito a ser construído por meio da educação - o camponês - a partir do qual será reconhecido como parte integrante da nação.

"Campo" também está largamente associado a uma identidade marcada pelo trabalho, incluindo, assim, camponeses, quilombolas, as nações indígenas e os diversos tipos de trabalhadores assalariados. A escola, específica para o "campesinato", deve, então, cooperar para a construção de uma consciência de pertencimento a um determinado espaço físico e social. Ou seja, a construção de tal identidade via educação deve servir para produzir conhecimentos significativos para o cotidiano camponês, reiterando a ideia de "campo" como "lugar de vida, onde as pessoas podem morar, trabalhar, estudar com dignidade de quem tem o seu lugar, a sua identidade cultural" (SOUZA, 2008, apud CHAVES, 2015, p.62). Embora a aposta de Chaves (2015) seja numa desejável ruptura "com a visão homogeneizadora do espaço do campo destinado ao fracasso e reservado ao latifúndio ou ao esquecimento" (CHAVES, 2015, p.62), o texto parece reverberar esses mesmos sentidos, uma vez que tem como estratégia argumentativa centralizar a discussão de constituição das escolas do campo no processo migratório dos camponeses para as cidades urbanizadas, reiterando a lógica da modernidade/colonialidade. Outra marca que corrobora com nossa posição, é a passividade como marcador do "campo" e de suas populações em relação às decisões econômicas e políticas sempre exteriores a ele - situação que só tem alteração, conforme o texto, a partir da década de 90 - tom que, talvez, tenha sido dado devido à opção de construção do texto centralizando a atenção em datas e textos legais.

Já a dissertação de Negri (2017) procurou apresentar os discursos que circulam sobre o “campo" em coleções didáticas do Programa Nacional do Livro Didático - Campo 2016 (PNLDCampo), destinadas ao primeiro segmento do Ensino Fundamental, através da análise de imagens sobre as "populações do campo" - ribeirinhos, caiçaras, pescadores artesanais, etc. Em seu texto 
introdutório, relata sua experiência como docente em uma comunidade de pescadores, fazendo emergir a dificuldade de lidar com os livros didáticos que não se adequavam à realidade local da ilha onde lecionava e enuncia: "não sabíamos que comunidades tradicionais de pescadores pertenciam ao campo. Assim, ao ingressarmos no Mestrado Profissional nos aprofundamos nessa temática, constatando que lecionamos numa escola do e no campo" (NEGRI, 2017, p.10). A potência deste relato remete-nos à multiplicidade de discursos que circulam nos mais diversos espaços sociais e que disputam o poder de significação sobre o "campo". A constatação de Negri desvela-nos a dispersão do significado de "campo" já sinalizada em Chaves (2015), dando-se, não em seu local de trabalho, junto à comunidade de pescadores. Também não se deu em algum tipo de inserção em movimento social ligado aos moradores locais onde a escola se situava. Diferente, por exemplo, de Chaves (2015), que vincula sua pesquisa às memórias afetivas de sua criação (CHAVES, 2015, p.1), em Negri (2017), deu-se em outro espaço; na universidade, por meio de um curso de pós-graduação em Educação onde travou contato com uma série de autores e legislações que subscrevem o que se deve entender por "campo", "educação do e no campo", "povos do campo".

Essa disputa por significação também aparece em outros momentos: quando se apresenta um apanhado de leis, resoluções e pareceres e, ao mesmo tempo, se problematiza a substituição de "rural" por "campo" para caracterização de projetos educacionais. A tentativa de distinção entre "rural" e "campo" traz disputas ao enfatizar como o "campo" deve ser significado:

[...] Educação do campo e não mais educação rural ou educação para o meio rural. A proposta é pensar a educação do campo como processo de construção de um projeto de educação dos trabalhadores do campo gestado desde o ponto de vista dos camponeses e da trajetória de lutas de suas organizações. (CALDART, 2004, p. 13 apud NEGRI, 2017, p.13).

Assim, tenta-se demarcar o suposto fracasso das políticas educacionais de integração das "populações do campo" à nação - sob o termo educação rural - cujo efeito seria o não reconhecimento de suas identidades visto a manutenção da desvalorização de seu modo de pensar, de viver e, em especial, das formas de trabalho, dada a prevalência de um modelo educacional associado ao capitalismo.

Em nosso argumento, o mecanismo moderno e colonial de produção do "Outro" é acessado, mais uma vez, por meio da configuração do binário rural/campo, no qual a produção da identidade camponesa parece conflitar com outras formas de estar no "campo", como o agronegócio. E 
deste enfrentamento, agrega-se ao discurso a defesa à educação "no e do campo" como meio de garantia de direitos sociais para as "populações do campo", corroborando, como corolário, o signo do atraso contra o qual se busca criticar. A aposta na construção do binômio campo/ rural parece reeditar as disputas entre rural/urbano ou campo/cidade. O rural, quando associado ao agronegócio, já não cabe completamente como lugar do atraso visto à integração com novas tecnologias e ao mercado internacional. Todavia, essa significação não teria mudado para os "povos do campo", cujas condições materiais não teriam se alterado e continuariam a povoar o imaginário social como atrasados, graças ao fracasso das políticas educacionais em promover sua emancipação em relação à exploração econômica e a exclusão social ou a reconhecer seus modos de vida num movimento de inclusão de suas identidades à plena condição cidadã.

A pesquisa de Vieira (2013), por sua vez, objetivou verificar em documentos oficiais e livros didáticos do PNDL-Campo 2013 se e como foram apropriados conceitos e temáticas, produzidos pela Educação do Campo, pelos movimentos sociais e de pesquisas acadêmicas. Mais uma vez o binômio rural versus campo faz-se presente marcando a arena de oposição política entre agendas estatais e dos movimentos sociais. O termo rural é usado para qualificar as propostas do Estado para a educação, datadas do início do século XX; enquanto "campo" qualifica a perspectiva dos movimentos sociais para a educação desde a sua organização na década de 1990. A pesquisa situa-se na trajetória da autora enquanto moradora de uma cidade agrícola, professora em escolas do campo, inclusive atuante como professora e coordenadora de escola em assentamentos do MST e também de sua trajetória acadêmica. Vieira (2013) dedica-se, de fato, a pensar a Educação do Campo enquanto produção conceitual e teórica do MST. Por isso, opta por realizar uma contextualização histórica, apontando o caminho em que este movimento social se constituiu e construiu suas pautas de luta e inseri-lo na temporalidade de longa duração, na qual se instala a questão agrária no Brasil e episódios como a Guerra de Canudos e a Guerra do Contestado, ocorridas no final do século XIX, início do século XX. Portanto, o MST não seria o movimento social precursor, mas engendrado pelas disputas de terra.

No esforço de tecer o fio da história de ocupação desigual da terra no Brasil, o texto de Vieira (2013, p.21) apresenta algumas inconsistências historiográficas que marcam frases como, por exemplo, "nossa história de povo brasileiro explorado, desde a colonização "país marcado pela concentração de terras desde a colonização, que data do ano de 1500", "os Portugueses aqui chegaram [...], impondo as leis e vontades políticas da Monarquia portuguesa. Os europeus invadiram o território, expropriando a população indígena que aqui habitava", que simplificam a história política, social e econômica do país e cria equivocadamente dicotomia sobre a constituição social brasileira, resumindo-nos entre nós (povo explorado) e eles (portugueses). Ao abordar a 
Lei de Terras de 1850 apropria-se da versão historiográfica filiada ao denominado paradigma paulista $^{3}$. Sobre isso, Vieira escreve,

Para Martins (2010), diferentemente do que ocorreu na colonização norteamericana, em que a lei permitia a ocupação da terra sem ônus, o Brasil 'inventou uma fórmula de coerção sobre o trabalho do homem livre': a terra se tornou cativa, escrava. Desta forma, o 'cativeiro da terra é a matriz estrutural e histórica da sociedade que somos hoje.' (p. 10). Ela não pode ser ocupada livremente, pois a terra é propriedade de alguém, ou do Estado, criando-se assim as condições geradoras de um modelo excludente.

Baseada na obra O cativeiro da terra, de José de Souza Martins (2010), que compreende a Lei de Terras como meio de assegurar os interesses dos grandes proprietários, tornando a terra cativa e fora de acesso aos imigrantes que viriam substituir os escravos na transição para a mão de obra livre, deixa de considerar produção historiográfica ${ }^{4}$ que aborda uma série de polêmicas envolvendo o texto legal: como a necessidade de comprovação da posse das terras devolutas por parte do Estado; o fato de que a lei assegurou, pelo mesmo princípio de comprovação de posse, o direito à terra por posseiros, fundamentando o usucapião; fomentou a prática da grilagem. E, mesmo, o modo como homens livres pobres fizeram uso desta lei para reivindicar a posse de suas terras. Deste modo, associa linearmente à lei a precariedade de políticas públicas destinadas as populações rurais:

Desta forma, o "cativeiro da terra é a matriz estrutural e histórica da sociedade que somos hoje" (p. 10). Ela não pode ser ocupada livremente, pois a terra é propriedade de alguém, ou do Estado, criando-se assim as condições geradoras de um modelo excludente. Em consequência, as populações rurais foram condenadas ao esquecimento pelas políticas públicas durante décadas, originando graves problemas no campo como a precariedade da escolarização oferecida às crianças e jovens da população rural (VIEIRA, 2015, p 21-22).

\footnotetext{
${ }^{3}$ Ver: MOTTA, Márcia (1998, 2001); FERREIRA, Renata (2009).

${ }^{4}$ Ver: MOTTA, Márcia (1998, 2001, 2004, 2006).
} 
Trago o texto da autora até aqui porque, ao discorrer sobre o tema, produz alguns sentidos de "campo" como: lugar de conflito, de exploração, lócus do poder econômico, da concentração de renda capitalista e de esquecimento do governo - todos sentidos que a própria Vieira (2013), Chaves (2015) e Negri (2017) atribuem ao paradigma rural, a ser substituído pelo paradigma do campo. A opção pela construção da narrativa deste modo parece ter como objetivo evidenciar o MST e demais movimentos sociais como protagonistas de mudanças de rumos nessa longa duração de disputas de terra. Mas ao fazê-lo cria uma temporalidade única que, paradoxalmente, não agrega a multiplicidade dos grupos sociais identificados como "populações do campo", por exemplo, indígenas, quilombolas, pescadores, caiçaras, ribeirinhos e outros.

Assim, coloca em cena uma única perspectiva possível dessa história camponesa - se assim podemos tratar - que também se confunde com a história da educação. Sobre a inclinação à educação como pauta política de reivindicação do MST - seja ela formal ou informal -, Vieira (2013) escreve,

\begin{abstract}
Embora organizações como esta não tenham surgido com o objetivo de resolver o problema da educação no Brasil, ao longo do tempo esta passou a ser também bandeira de luta. A organização do movimento logo se deu conta da importância da educação no processo da luta pela terra, pois para a organização crescer e atingir a dimensão que se almejava era preciso não só entender o contexto político, mas dominar também a linguagem escrita, o que conduziu a uma ênfase na educação de crianças, jovens e adultos. (VIEIRA, 2013, p.25)
\end{abstract}

Tal colocação lembra-nos Spivak (2010) quando trata da impossibilidade de fala do subalterno, posto que somente pode falar quando acessa às condições que o colonizador lhe coloca, não fala por si, só pode falar apenas enquanto subalterno. Neste sentido, questionome sobre o limite em que os discursos educacionais podem reiterar a produção de diferenças. Assim como Chaves (2015) e Negri (2017), Vieira (2013) apresenta sua perspectiva das políticas públicas educacionais direcionadas ao "campo". Detendo-se ao "ruralismo pedagógico", também discutido por Chaves (2015), ao caracterizar a introdução da educação rural na Constituição de 1934, atribui o incentivo à escolarização das populações rurais como estratégia de retardamento das migrações para os centros urbanos e o esvaziamento da mão de obra no campo. E afirma que "no seu interior os objetivos reais eram tirar o agricultor da marginalidade, da ignorância, transformar o Jeca Tatu em um assalariado preparado para o mundo industrial" (VIEIRA, 2013, p.30). "Campo" e "rural" mais uma vez aparecem alocados em posições inconciliáveis, já que para Vieira (2013) o currículo para as escolas rurais incorporava os princípios de desenvolvimento 
social e econômico urbano industrial, que estariam manifestos no Plano de Ensino Rural de 1954 e instituiriam um currículo que serviria de instrumento de reprodução de valores capitalistas, uma vez que funcionariam como "instrumento formador tanto de uma mão de obra disciplinada para o trabalho assalariado rural quanto de consumidores dos produtos agropecuários gerados pelo modelo agrícola importador" (RIBEIRO, 2012, p. 297 apud Vieira, 2013, p.32).

Aproximando-se, então, das décadas de 1970 e 1980, Vieira (2013) situa o MST como a oposição ao discurso desenvolvimentista, cuja luta também abrange a educação em vista de sua defesa por uma educação do campo. Para reforçar seu argumento, faz a seguinte citação de Caldart (2004), que nos parece elucidativa da vinculação estreita entre o discurso educacional e a produção de significados para o "campo":

\begin{abstract}
A materialidade de origem da Educação do Campo projeta / constrói uma determinada totalidade de relações que lhes são constitutivas. Antes (ou junto) de uma concepção de educação ela é uma concepção de campo: porque, neste caso, como pensamos o campo pensamos a educação; se pensarmos o campo como latifúndio não temos como pensar a Educação do Campo; se pensarmos a reforma Agrária como uma política social ou compensatória apenas, não vamos pensar em um sistema público de ensino. (CALDART, 2004, p.22 apud VIEIRA, 2013, p.33)
\end{abstract}

Nesse sentido, o "campo" estaria amalgamado tanto a concepções educativas como a projetos de desenvolvimento - seja ele identificado como "educação rural", seja ele identificado como "educação do campo". Em detrimento de um projeto de desenvolvimento do agronegócio, que representaria o status quo, o ideal de desenvolvimento do campo que habitaria as escolas projetaria o interesse dos camponeses; pois "no campo do grande latifundiário gradativamente deixaram e deixam de existir sujeitos, substituídos no trabalho mecanizado, é no campo da agricultura camponesa que se encontram e fazem sentido as escolas do campo, em toda a sua diversidade". (VIEIRA, 2013, 34). Assim, o desenvolvimento do campo, pensando segundo o anseio camponês, demandaria a Reforma Agrária como única possibilidade de efetivação de um projeto educacional válido para os povos do campo.

Ao imputar a originalidade do conceito de Educação do Campo ao MST repetidas vezes, Vieira (2013) proporciona-nos um deslocamento para pensar a Educação do campo como estratégia política utilizada por esses grupos para se fazerem ouvir quanto à sua principal demanda: a Reforma Agrária. Ainda que consideremos a manutenção de tudo aquilo que nos possibilitaria 
imaginar as "culturas camponesas", sem a posse da terra parte significativa de suas práticas e seu modo de vida estaria sob ameaça posto seu elo inerente. Como a educação se constitui de ideais como formação cidadã, desenvolvimento social e projeto de nação - ou seja, mobiliza todo um conjunto de princípios que interessam ao Estado - adentrar a este campo discursivo configura uma estratégia assertiva para reconduzir o enfrentamento por terra.

Diferente de Chaves (2015), Negri (2017) e Vieira (2013), a pesquisa de Carmo (2015) dedica-se a pensar o espaço rural e suas representações no livro didático, sem que o rural esteja associado ao paradigma da educação rural, mas enquanto espaço não-estático e de transformação em comparação com as representações das cidades. De igual modo, atenta-se para o "campo" não apenas enquanto construção teórica atribuída aos movimentos sociais, mas também onde se situam os principais embates por reforma agrária, os conflitos pela posse da terra em cujo passado e presente de enfretamentos se constrói a identidade camponesa. Seu olhar para os livros didáticos tem por interesse perceber se o rural captado privilegia a perspectiva da educação do campo, que demanda o reconhecimento de uma identidade defendida como diferenciada, ou se aponta para sua heterogeneidade de formas e transformações que sofre.

Desse modo, em Carmo (2015), "campo" e "espaço rural" são concebidos como distintos não porque se opõem, mas por estarem associados a diferentes matrizes teóricas, presumindo "o campo como espaço de cultura, cotidiano, economia diferenciados dos centros urbanos, permitindo inferir a existência de uma identidade camponesa; e o rural plural, transformado e em constante transformação" (CARMO, 2015, p.20). Assim, propõe problematizar a construção de representações do espaço rural, ponderando aspectos como: as diferenças climáticas e diversidade cultural de um país com dimensões continentais como o Brasil, bem como o fato de não haver critérios específicos para categorizar uma área como urbana, tomando como possibilidade avaliar o nível de interferência humana sobre o meio. Como crítica, infere que o "campo" é comumente tratado como espaço isolado e, portanto, propõe que deva ser analisado pela relação que estabelece com pessoas, considerando a divisão social e territorial do trabalho e a interdependência com outros espaços.

No esforço de construir uma significação para o "campo" priorizando o sentido de espaço dinâmico que se constitui em relações, privilegia a perspectiva de que a partir da maior interação do "campo" com os centros urbanos, em vez de tender à superação pela urbanização, haveria uma reformulação econômica no que tange às atividades, que passariam a abarcar as diferentes transformações ocorridas nos diferentes espaços rurais agregando outras funções como, por exemplo, a preservação do meio ambiente, o turismo, o lazer, a preservação do patrimônio cultural. A relação entre "campo" e "cidade", em vez de ser marcada pela superação ou por 
oposição, produziria outra ruralidade. O binômio campo/cidade é pensado pelos geógrafos com quem Carmo (2015) constrói seu texto enquanto um mito produzido pela sociologia rural, tal como a concepção de que o campo seria suprimido pelas cidades industrializadas. Podemos ir além.

Acreditamos que a construção do binômio campo/cidade não se restringiu à sociologia rural, marcando o pensamento social e econômico brasileiro nas décadas de 1950 e 1960 . E, tampouco, é exclusividade brasileira ponderações sobre o tema em suas implicações econômicas, políticas e culturais. O crítico literário inglês Raymond Williams (1989), por exemplo, já mostrara em seu estudo, intitulado O campo e a cidade na História e na Literatura, como os dois termos foram ganhando outros sentidos em diferentes momentos e lugares:

\begin{abstract}
O campo passou a ser associado a uma forma natural de vida - de paz, inocência e virtudes simples. À cidade associou-se a ideia de centro de realizações de saber, comunicações, luz. Também constelaram-se poderosas associações negativas: a cidade como lugar do barulho, mundanidade e ambição; o campo como lugar do atraso, ignorância e imitação. O contraste entre campo e cidade como formas de vida fundamentais, remonta à Antiguidade Clássica. (WILLIAMS, 1989, p.11)
\end{abstract}

A isto poderíamos acrescentar: não seria uma marca da colonialidade em funcionamento? A invenção do "campo" como Outro da cidade não seria um suporte discursivo para a temporalidade de uma narrativa histórica que aponta para o progresso? Segundo Carmo (2015), os livros didáticos analisados por ele também não privilegiariam a transformação do "campo" e a emergência de novas ruralidades, mas seriam predominantes quatro representações: o espaço destinado à prática agrícola; espaço onde predominam indivíduos em condição de miséria ou subalternos a outros grupos sociais; lugar de predomínio econômico e político dos grandes proprietários rurais; espaço marcado por conflitos sociais, cabendo questionar: estas representações do "campo" estariam associadas a algum tipo de tradição que se consolidou na historiografia didática? Teria relação com as referências na historiografia acadêmica utilizadas pelos autores dos livros? Com relação a preocupação de Carmo (2015) quanto à adequação dos livros às demandas estabelecidas pela Educação do campo, conclui que não atenta para a dita realidade diferenciada dos alunos do "campo", e tampouco aproxima-se das expectativas do Movimento de Educação do Campo no que tange à conformação da educação à realidade camponesa. E faz a seguinte crítica: 
Não se pode esquecer que a proposta de educação do campo, conforme defendida por diferentes autores já citados, é presente também na academia, principalmente nos cursos de formação de pedagogas/ pedagogos. Contudo, aparentemente, seus defensores ainda não se abriram às contribuições de conceitos que permitiriam uma análise mais profunda sobre a configuração agrária brasileira. [...] não teria a Educação do Campo, portanto, que passar por uma autoavaliação? (CARMO, 2015, p.102)

\begin{abstract}
A isto podemos somar a reflexão sobre a trajetória ambivalente da Educação do Campo, ou seja: a bandeira pela educação do/no campo, defendida como importante meio de emancipação de suas populações, creditada ao MST, pode ser entendida, na trajetória deste movimento social, como o deslocamento da disputa pelo reconhecimento do Estado à demanda por terra. Assumindo o discurso de que a educação possibilita a condição de plena cidadania e de integração à nação, a Educação do Campo referenda a política de identidade e a especificidade da identidade camponesa, criando demanda específica por educação e, finalmente, por terras, através de diversos textos legais aprovados.
\end{abstract}

\title{
Textos legais educação e identidade e reconhecimento e direitos sociais e cidadania...
}

Por meio dos trabalhos de Chaves (2015), Negri (2017), Vieira (2013) e Carmo (2015), travamos contato com diferentes textos legais - dentre pareceres e resoluções - que tratam do atendimento às "populações do campo". Com uma breve abordagem de alguns trechos, esperamos dar prosseguimento ao debate ao qual nos propomos que é discutir o vínculo entre os discursos educacionais e a cidadania, apontando para suas ambivalências e esboçando algumas questões que consideramos importante no que concerne ao debate da diferença. Do percurso que podemos fazer pela legislação vigente, começamos pela Lei de Diretrizes e Bases (LDB) de 1996. Ao tomar seu artigo 28, compreendemos que já tratava do atendimento às "populações do campo" sem, no entanto, associar o direito à educação a alguma política de identidade. Ao contrário, utiliza-se do termo "rural" já combatido pelos movimentos sociais do "campo", desde o final da década de 1988 conforme apontaram Chaves (2015), Negri (2017) e Vieira (2013). De acordo com o texto legal,

Art. 28. ${ }^{\circ}$ - Na oferta de Educação Básica para a população rural, os sistemas e ensino promoverão as adaptações necessárias à sua adequação às peculiaridades da vida rural e de cada região, especialmente: I - conteúdos curriculares e 
metodologias apropriadas às reais necessidades e interesses dos alunos da zona rural; II - organização escolar própria, incluindo adequação do calendário escolar às fases do ciclo agrícola e às condições climáticas; III - adequação à natureza do trabalho na zona rural (BRASIL, 1996).

Entretanto, as narrativas dos textos legais começam a mudar, provavelmente, aquiescendo às disputas políticas, como podemos ler em trecho do Parecer n. 36/2001 (BRASIL, 2001):

A educação do campo, tratada como educação rural na legislação brasileira, tem um significado que incorpora os espaços da floresta, da pecuária, das minas e da agricultura, mas os ultrapassa ao acolher em si os espaços pesqueiros, caiçaras, ribeirinhos e extrativistas. O campo, nesse sentido, mais do que um perímetro não urbano, é um campo de possibilidades que dinamizam a ligação dos seres humanos com a própria produção das condições da existência social e com as realizações da sociedade humana (BRASIL, 2001, p. 01).

O Parecer incorpora alguns elementos discursivos da Educação do Campo e confere reconhecimento de algumas de suas demandas e características, como a dicotomia rural/campo, que também constam na Resolução CNE/CEB 1, de 3 de abril de 2002, que institui as Diretrizes Operacionais para a Educação Básica nas Escolas do Campo, tratando da identidade da escola do campo,

\begin{abstract}
A identidade da escola do campo é definida pela sua vinculação às questões inerentes à sua realidade, ancorando-se na temporalidade e saberes próprios dos estudantes, na memória coletiva que sinaliza futuros, na rede de ciência e tecnologia disponível na sociedade e nos movimentos sociais em defesa de projetos que associem as soluções exigidas por essas questões à qualidade social da vida coletiva no país (BRASIL, 2002, p.32).
\end{abstract}

Ou no trecho do documento de Referência para uma Política Nacional de Educação do Campo (BRASIL, 2004), que reconhece através do texto institucional tanto a Educação do Campo, como o "campo", como gerador de demandas cujos direitos sociais não estariam sendo plenamente contemplados, mas cuja legitimidade é reconhecida pelo Estado, 
[...] essa categoria de educação traz um conjunto de conhecimentos e práticas que instiga as políticas a compreenderem o campo como um espaço emancipatório, como um território fecundo de construção da democracia e da solidariedade, porque se transformou no lugar não apenas das lutas pelo direito à terra, mas também pelo direito à educação, à saúde, entre outros, e essas lutas acabaram por colocar na pauta novas políticas culturais, econômicas e ambientais para o campo, mas não apenas para o campo. (BRASIL, 2004, p. 36).

Vislumbra-se, em mais um documento, a eterna briga do mundo do Senhor Cidadão, que possui o reconhecimento de sua identidade, de seu modo de vida, mas continua com sua vida amarga. Na Resolução $\mathrm{n}^{\circ}$ 2, de 28 de abril de 2008, que estabelece as diretrizes complementares, normas e princípios para o desenvolvimento de políticas públicas de atendimento da Educação Básica do Campo, não há distinção entre "rural" e "campo" e outros grupos são incluídos à identidade camponesa; como assentados e acampados da Reforma Agrária e indígenas:

[...] Destina-se ao atendimento às populações rurais em suas mais variadas formas de produção da vida - agricultores familiares, extrativistas, pescadores artesanais, ribeirinhos, assentados e acampados da Reforma Agrária, quilombolas, caiçaras, indígenas e outros (BRASIL, 2008).

E, ainda reitera que "a organização e o funcionamento das escolas do campo respeitarão as diferenças entre as populações atendidas quanto à sua atividade econômica, seu estilo de vida, sua cultura e suas tradições" (BRASIL, 2008).

Sentidos ambivalentes de "campo" são esboçados como correspondendo a um projeto educacional emancipador, via construção e reconhecimento da identidade camponesa. Ao passo em que se volta contra a homogeneização cultural e a padronização das propostas educativas que preconizam a formação do cidadão e o fortalecimento de vínculos sociais e identitários nacionais alijando as populações do campo por seus modos de vida diferentes, defende o fortalecimento de uma identidade através de "escolas com um projeto político-pedagógico vinculado às causas, aos desafios, aos sonhos, à história e à cultura do povo trabalhador do campo" (FERNANDES, CERIOLI e CALDART, 2005, p. 27 apud NEGRI, 2017, p.13). Entretanto, ao considerar "a história" e "a cultura do povo trabalhador do campo", é possível escapar à homogeneização quando o movimento pende para criar uma coesão e unidade entre grupos com trajetórias e temporalidades 
distintas? Não seria este um mecanismo moderno de produção da diferença colonial (MIGNOLO, 2008) em funcionamento? Isto é, acionar a produção de categorias classificatórias não seria um modo de reiterar o movimento de produção de hierarquizações que cristalizam o lugar do Outro como falta ou como excesso - o mesmo do qual se pretenderia escapar?

Parece-nos que para os "povos do campo" terem acesso a direitos sociais, como educação, precisam acessar tal identidade, que se institucionaliza através das legislações e discursos educacionais. Por exemplo, através do Decreto $\mathrm{n}^{\circ} 7.352$, de 4 de novembro de 2010, que dispõe sobre a política de educação do campo e o Programa Nacional de Educação na Reforma Agrária - PRONERA, que define quem são as populações do campo, a escola do campo, turmas do campo e os princípios da escola do campo, reeditando uma série de compromissos e deveres do Estado que já aparecerem em outros documentos, mas que provavelmente não foram cumpridos na íntegra:

[...] § 1o Para os efeitos deste Decreto, entende-se por: I - Populações do campo: os agricultores familiares, os extrativistas, os pescadores artesanais, os ribeirinhos, os assentados e acampados da reforma agrária, os trabalhadores assalariados rurais, os quilombolas, os caiçaras, os povos da floresta, os caboclos e outros que produzam suas condições materiais de existência a partir do trabalho no meio rural; e / II - Escola do campo: aquela situada em área rural, conforme definida pela Fundação Instituto Brasileiro de Geografia e Estatística - IBGE, ou aquela situada em área urbana, desde que atenda predominantemente a populações do campo. [...] (BRASIL, 2010).

A cerca da legislação está posta; construída na consonância dos movimentos sociais e de mobilização dos discursos educacionais, identificou com um mesmo termo "populações do campo" uma série de grupos com modos de vida distintos e ontologias distintas - de povos da floresta, quilombolas, ribeirinhos a "outros que produzam suas condições materiais de existência a partir do trabalho rural". Quem poderiam ser esses "outros"?

No Dicionário da Terra, organizado pela historiadora Márcia Motta (2010), o termo campesinato foi escrito por Grynzpan (2010) e aparece como uma identidade cuja construção seria resultado da organização e mobilização de trabalhadores rurais que lutam por terras e por direitos. De acordo com Grynzpan (2010), podem ser considerados "camponeses": pequenos proprietários, assalariados, posseiros, parceiros, arrendatários, foreiros, colonos. Há ainda aqueles que se definem como camponeses sem que vivam exclusivamente da terra pois compõem 
sua renda com trabalhos urbanos. Ou, ainda, aqueles que explore seu lote empregando a mão de obras de terceiros. Motta e Zarth (2008, p.9), ao considerarem as pesquisas que destacam a organização política e diversidade dos que objetivam a condição camponesa no Brasil, ampliamse "campesinato" abrangendo,

[...] proprietários e os posseiros de terras públicas e privadas; os extrativistas que usufruem os recursos naturais como povos das florestas, agroextrativistas, ribeirinhos, pescadores artesanais e catadores de caranguejos que agregam atividade agrícola, castanheiros, quebradeiras de coco babaçu, açaizeiros; os que usufruem os fundos de pasto até os pequenos arrendatários nãocapitalistas, os parceiros, os foreiros e os que usufruem a terra por cessão; quilombolas e parcelas dos povos indígenas que se integram a mercados; os serranos, os caboclos e os colonos assim como os povos das fronteiras no sul do país; os agricultores familiares mais especializados, integrados aos modernos mercados, e os novos poliprodutores resultantes dos assentamentos de reforma agrária. (MOTTA; ZARTH, 2008, p. 09)

Deste modo, parece-nos que o discurso emancipador e salvacionista pedagógico não dá conta de abarcar tantos mundos diferentes, soando bastante violento a conformação à uma trajetória única, sob o manejo das teorias pedagógicas. Todo o movimento que estas pesquisas trazem, a partir das mudanças de legislações para incorporar as demandas das "populações do campo", faz-nos, mais uma vez, chamar Krenak (2018) ao texto: "tem que ralar na mais desolada condição de cidadão para se erguer como um sem-terra” (KRENAK, 2018, p.17).

\section{Considerações Finais}

A matriz de inteligibilidade política dentro da qual as pesquisas operam caracteriza-se por ser, certamente, dualista, mas também, e de forma paradoxal, por expandir. No entanto, como escreveu Hall (2013),

Os binarismos políticos não estabilizam permanentemente o campo do antagonismo político [...], nem conferem a este uma inteligibilidade transparente. [...] consequentemente, as posições políticas não são fixas, não se repetem de uma situação histórica a outra [...]. (HALL, 2013, p.104) 
Com efeito, a repetição constante dos binários que inteligibilizam a luta políticas das pesquisas sinaliza para sua instabilidade. Com Bhabha (2014), apostamos no pensamento de fronteira, isto é, se tais binômios só existem em relação, se ambos os termos são dependentes um do outro, nenhuma dominação cultural é tão poderosa a ponto de minar os sistemas culturais locais. E nenhum sistema cultural local fica imune ao colonialismo. A diferença não subsiste à dominação e a dominação não acaba com a diferença. Trata-se, assim, de uma relação ambivalente. Talvez, por isso, a lógica dos binômios oprimido/opressor, europeu/não-europeu, europeu-moderno/nós, rural/urbano, atraso/progresso, campo/cidade, rural/campo, não apenas não seja tão de oposição quanto pode soar como espaços cristalizados que pretendem objetivar a diferença. Com Lugones (2014, p.936), podemos pensar que o cerne da modernidade colonial foi produzir como hierarquia dicotômica central a diferença entre humano e não humano e que tem operado como um dispositivo de "alterocídio, isto é, construindo o Outro não como semelhante a si mesmo, mas como objeto intrinsecamente ameaçador, do qual é preciso proteger-se, desfazerse, ou que, simplesmente, é preciso destruir, devido a não conseguir assegurar seu controle total" (MBEMBE, 2014, p.26).

É, aqui, que o "campo" como "o Outro" da "cidade" ocupa um lugar ambivalente, pois, ao deixar vir à tona aquilo que lhe falta à identidade, é apresentado como lócus da incompletude e ausência, seja em aspectos econômicos ou educacionais. Torna-se ambivalente porque essa ausência só existe no confronto contínuo entre "campo" e "cidade", nos quais ambos concorrem por mão de obra, modos de vida, ideais de progresso e projetos educacionais bem ou malsucedidos para as "populações do campo". Por outra via, para dar conta de um projeto de educação para as "populações do campo", aciona-se outra oposição, agora construída entorno do confronto entre "rural" e "campo". O binômio campo/rural ganha força nos discursos educacionais, entretanto, no mesmo movimento que campo/cidade continua perpassando o imaginário. A construção da oposição entre "rural" e "campo" promove dois deslocamentos. Primeiro, disputa-se projetos de identidade - o camponês - a ser construída por meio da educação que lhe garantirá os meios para tornar-se parte integrante da nação. Nesse sentido, tal oposição também reinstaura a ideia de ausência (de uma identidade a ser construída). Por outro lado, "rural" é deslizado para agronegócio, assumindo-se a ideia de industrialização, mecanização da produção e concentração de renda e lucro, características do avanço capitalista na produção agropecuária, como suas marcas.

O incômodo que perpassa este artigo tem a ver com a reflexão de que, entre as pesquisas educacionais analisadas, a elaboração de projetos de emancipação para as "populações do campo", entendida como a luta política que a pesquisa em educação sobre o "campo", pode e deve realizar, termina por recorrer aos mesmos mecanismos coloniais de produção de diferença. Isso porque os mantém alijados, por princípio e fundamento, dos direitos que demandam - muitas 
vezes do direito à vida - posto que inventados como Outros, logo, desde sempre, excluídos da nação (que os deveria reconhecer como cidadãos) ou "diferentes" (da cidade e dos projetos agropecuários). Ou seja, tais dispositivos funcionam produzindo categorias homogêneas, dicotômicas e hierárquicas que caracterizam o modo pelo qual a modernidade colonial organiza ontologicamente o mundo, isto é, como promove uma terrível e violenta simplificação. São modos de produzir inteligibilidade da luta política da pesquisa em educação que limitam as possibilidades do que currículo pode vir a ser quando o "campo" é atrelado a uma política de identidade chancelada pelo Estado. Enquanto presume-se a conquista do reconhecimento da identidade camponesa por parte do Estado via concessão de direitos, legitima-se e atualizamse as relações de poder que, há muito, caracterizam a modernidade/colonialidade; aquelas que levam às vidas a performar certa pobreza de mundo para serem reconhecidas enquanto vidas. Não é esse encurralamento em cercas físicas e existências que nos caberia suspeitar quanto se tratar de pensar o "campo"?

\section{REFERÊNCIAS}

ANHORN, Carmen Teresa Gabriel; COSTA, Warley da. Políticas da Diferença e Hegemonia: diálogos possíveis. Educação e Realidade. Porto Alegre, v. 36, n.1, p. 127-146, jan./abr., 2011.

BHABHA, Homi. O local da cultura. Tradução de Myriam Ávila, Eliana Lourenço de Lima Reis, Gláucia Renata Gonçalves. 2ª ed. Belo Horizonte: Editora UFMG, 2014. 395p.

BRASIL. Lei $n^{0} 9.394$ de 20 de dezembro de 1996. Lei de Diretrizes e Bases da Educação Nacional. Disponível em: http://www.planalto.gov.br/ccivil_03/Leis/19394.htm. Acessado em: 07 de agosto de 2018.

BRASIL. Parecer n. 36/2001. Diretrizes operacionais para a Educação Básica nas escolas do campo. Brasília/DF, 2001.

BRASIL. CNE. Resolução CNE/CEB 1/2002. Diário Oficial da União, Brasília, 9 de abril de 2002. Seção 1, p. 32.

BRASIL. Referência para uma Política Nacional de Educação do Campo. Brasília, DF, 2004. 
BRASIL. Resolução n. 02, de 28 de abril de 2008. Estabelece Diretrizes Complementares, normas e princípios para o desenvolvimento de políticas públicas de atendimento da Educação Básica do Campo. Brasília, DF, 2008

BRASIL. Decreto n. 07.352, de 4 de novembro de 2010. Dispõe sobre a política de educação do campo e o Programa Nacional de Educação na Reforma Agrária - PRONERA. Brasília, DF, 2010.

BUTLER, Judith. O que é a crítica? Um ensaio sobre a virtude em Foucault. Tradução de Gustavo Hessmann Dalaqua. Cadernos de Ética e Filosofia Política, n: 22, 2013. Disponível em: http://www.revistas.usp.br/cefp/article/view/59447/62615. Acesso em: 14 de junho de 2018.

BUTLER, Judith. Corpos em aliança e a política das ruas: notas para uma teoria performativa de assembleia. Trad. de Fernanda Siqueira Miguens. Rio de Janeiro: Civilização Brasileira, 2018.

CALDART, Regina. A escola do campo em movimento. Em: ARROYO, M.G.; CALDART, R.; MOLINA, C.M. (Org). Por uma educação do campo. Petrópolis: Vozes, 2004.

CARMO, Francisco Gildevan Holanda do. A representação do espaço rural e dos povos do campo no livro didático de história: uma imagem sob a ótica da Educação do Campo ou da Pluralidade rural? 2015. 108p. Dissertação (Mestrado em Ciências Sociais e Humanas). Universidade do Estado do Rio Grande do Norte. Mossoró, 2015.

CARVALHO, José Murilo de. Cidadania no Brasil: o longo caminho. $23^{\text {a }}$ edição. Rio de Janeiro: Civilização Brasileira, 2017.

CASSIANO, Célia C de Figueiredo. Aspectos políticos e econômicos da circulação do livro didático de História e suas implicações curriculares. História, 23 (1-2), S. Paulo, 2004.

CHAVES, Edilson Aparecido. A presença do livro didático de História em aulas do ensino médio: estudo etnográfico em uma escola do campo. 2014. 226p. Tese (Doutorado em Educação). Universidade Federal do Paraná. Curitiba, 2015. 
CHOPPIN, Alain. História dos livros e das edições didáticas: sobre o estado da arte. Educação e Pesquisa, São Paulo, v. 30, n.3, pp. 549-566, set./dez. 2004.

ESCOBAR, Arturo. Mundos y conocimientos de outro modo. Tábula Rasa, v. 1, p.51-86, 2003.

ESCOBAR, Arturo. La invención del Tercer Mundo. Construcción y deconstrucción del desarrollo. Caracas: Fundación Editorial, 2007.

FERREIRA, Renata Telha. História da agricultura brasileira: um domínio historiográfico em construção. 2009. 35p. Monografia (Especialização em História do Brasil). Universidade Federal Fluminense. Niterói, 2009.

FERNANDES, Bernardo M.; CERIOLI, Paulo R.; CALDART, Roseli S. "Primeira Conferência Nacional 'Por uma educação básica do campo': texto preparatório”. In: ARROYO, Miguel Gonzalez; CALDART, Roseli Salete; MOLINA, Mônica Castagna. Por uma educação do campo. Petrópolis: Vozes, 2004.

GRYNZPAN, Mario. “Campesinato” In MOTTA, Márcia. Dicionário da Terra. Rio de Janeiro: Civilização Brasileira, 2010.

GROSFOGUEL, Ramón. Para descolonizar os estudos de economia política e os estudos póscoloniais. Revista Crítica de Ciências Sociais, n. 80, p.115-147, 2008.

HALL, Stuart. Quando foi o pós-colonial? Pensando no limite. In: Da diáspora: identidades e mediações culturais. Belo Horizonte: Editora da UFMG, 2003. 116-123.

HARTOG, François. Crer em História. Trad. Camila Dias. B. Horizonte: Autêntica Editora, 2017.

KRENAK, Aílton. A Potência do Sujeito Coletivo. Parte I. Revista Periferias. R de Janeiro, 2018.

LOPES, Alice Casimiro. Currículo e epistemologia. Ijuí: Unijuí, 2007.

LUGONES, María. Rumo ao feminismo descolonial. Estudos Feministas, Florianópolis, v. 22(3), p. 935-952, setembro-dezembro/2014. 
MACEDO, Elizabeth. Currículo como espaço-tempo de fronteira cultural. Revista Brasileira de Educação, v. 11 n. 32 maio/ago. 2006.

MACEDO, Elizabeth. Mas a escola não tem que ensinar? Conhecimento, reconhecimento e alteridade na teoria do currículo. Currículo sem Fronteiras, v.17, n.3, set/dez 2017.

MBEMBE, Aquile. Crítica da razão negra. $3^{\mathrm{a}}$ ed. Portugal: Antígona, 2014.

MEYER, D. e PARAÍSO, M. Metodologias de pesquisas pós-críticas ou sobre como fazemos nossas investigações. In: MEYER, D. e PARAÍSO, M. (org.). Metodologias de pesquisas póscríticas em educação. 2.ed. Belo Horizonte: Mazza Edições, 2013.

MIGNOLO, Walter. La opción de-colonial. Tábula Rasa, Bogotá, Colômbia, n. 8: 243-281, Janeiro/Junho 2008.

MOTTA, Márcia Maria Menendes. Nas fronteiras do poder: conflito de terra e direito à terra no Brasil do século XIX. Rio de Janeiro: Vício de Leitura; Arquivo Público do Estado do Rio de Janeiro, 1998.

MOTTA, Márcia Maria Menendes. Movimentos Rurais nos oitocentos: uma história em reconstrução In: Estudos Sociedade e Agricultura, CPDA, 16, abril 2001: 113-128.

MOTTA, Márcia Maria Menendes. Caindo por Terra: um debate historiográfico sobre o universo rural do oitocentos In: Lutas e Resistências, v.1, pp. 42-59. Londrina, ,2006,

MOTTA, Márcia; Zarth, Paulo (Org.). Formas de resistência camponesa. Visibilidade e diversidade de conflitos ao longo da história. v 1 São Paulo: Editora da UNESP, 2008.

NEGRI, Licia Bonsi. Coleções didáticas do PNLD- Campo 2016: um discurso em análise. 2017. 78 p. Dissertação (Mestrado Profissional em Educação). Universidade Federal de São Carlos. São Carlos, 2017.

RANNIERY, Thiago. Vem cá, e se fosse ficção? Práxis Educativa (UEPG. ONLINE), v. 13, p. Ahead of print, 2018. 
SILVA, Marco Antônio. A fetichização do livro didático no Brasil. Educação e Realidade, Porto Alegre, v. 37, n. 3, p. 803-821, set./dez. 2012. Disponível em: http://www.ufrgs.br/edu_realidade

SPIVAK, Gayatry G. Pode o subalterno falar? Tradução de Sandra Regina Goulart Almeida, Marcos Feitosa. Belo Horizonte: Editora UFMG, 2010.

STENGERS, Isabelle. A proposição cosmopolítica. Revista do Instituto de Estudos Brasileiros, Brasil, n. 69, p. 442-464, abr. 2018. DOI: http://dx.doi.org/10.11606/issn.2316-901X. v0i69p442-464.

TIERRA, Pedro. A pedagogia dos aços. Brasília, 25/04/96. Disponível em: https://www.escritas. org/pt/t/9620/a-pedagogia-dos-acos. Acesso em: 14 de junho de 2018.

VIEIRA, Edilaine Aparecida. Livros didáticos para Escolas do Campo: aproximações a partir do PNLD Campo-2013. 2013. 157p. Dissertação (Mestrado). Universidade Federal do Paraná. Curitiba, 2013.

WILLIAMS, Raymond. O Campo e a Cidade: na história e na literatura. Trad. Paulo Henrique Britto. São Paulo: Companhia das Letras, 1989. 